\title{
Effect of continuous vibration on nociceptive flexor reflexes
}

\author{
C UMHUR ERTEK IN A N DENIZ A KÇALI \\ From the Department of Neurology, Medical School Hospital, Bornova, Izmir, Turkey
}

SUMMARY The effects of continuous segmental vibration on the biceps femoris (BF) nociceptive flexor reflexes elicited by painful electrical stimulation of the sural nerve at the ankle were investigated in 25 normal subjects. During vibration of $100 \mathrm{~Hz}$ frequency, applied either on ipsilateral or contralateral foot skin, the nociceptive BF flexor reflexes increased in amplitude. Marked facilitation was prolonged even 20 minutes after vibration ceased. Pain scnsation described by subjects did not change significantly cxcept that radiation of pain was reduced in some cases. The results could not be explained by current views of reflex sensitisation, dishabituation, or the gate control theory.

When vibration is applied to a limb, the tendon jerks are reduced or abolished (Eklund and Hagbarth, 1965; DeGail et al., 1966; Rushworth and Young, 1966). This classical effect of vibration on the myotatic reflexes has been investigated from many angles but little is known about the effect of vibration on the nociceptive flexor reflexes on the lower limb. Since painful single electrical pulses applied to the sural (Hugon, 1967, 1973) or posterior tibial nerves (Ertekin et al., 1975) always evoke nociceptive reflex responses from the ipsilateral biceps femoris muscle monitored by EMG, it would be interesting to investigate the behaviour of such a polysynaptic flexor reflex by segmental vibration, and this kind of study may be expected to show the interaction between large myelinated afferent nerve fibres activated by vibration and small myelinated (that is, A-delta group) and C fibres activated by a single painful electrical pulse to the sural nerve. Such an electrophysiological study, albeit not refined, could also test the gate control theory (Melzack and Wall, 1965) in normal human subjects.

In this study, the effect of segmental vibration on the biceps femoris (BF) nociceptive reflexes has been investigated systematically in 25 normal young subjects. It will be demonstrated that the nociceptive flexor reflex is facilitated by segmental vibration applied cutaneously, whereas the perception of pain sensation is not significantly modified.

Address for reprint requests: Dr Cumhur Ertekin, Department of Neurology, Medical School Hospital, Aegean University, Bornova, Izmir, Turkey.

Accepted 19 December 1977

\section{Methods}

Twenty-five normal healthy volunteers (six females, 19 males, 21 to 25 years of age with a mean age of 22.9 years) were examined. They were all students with no neurological or psychological complaints and disorders.

The subjects lay supine on a firm examination table. Their legs were left bare and no attempto was made to immobilise them. They were informed of the general nature of the experiment but not of specific results to be expected. After the experiment, the sensations felt and their possible alterations during the investigations were described in detail by the subjects and were recorded and compared with the electrophysiological data. The technique for evoking the biceps femoris nociceptive flexor reflex was described by Ertekin et al. (1975). The only difference from the method previously used was stimulation of the sural nerve instead of the posterior tibial nerve. By using surface bipolar stimulating electrodes (DISA $13 \mathrm{~K}$ $62)$, single rectangular $(1.0 \mathrm{~ms})$ electrical shocks were applied once per second to the nerve trunk behind the lateral malleolus. The pulse duration was sufficient to cause a painful sensation to the subject if the stimulus intensity was adequately adjusted. The recording site was in the short head of the biceps femoris muscle (BF), ipsilateral to the painful stimulation. A concentric needle electrode (DISA $13 \mathrm{~K} \mathrm{03)} \mathrm{was} \mathrm{used,} \mathrm{and} \mathrm{its} \mathrm{pos-}$ ition was adjusted to give a minimal movement artefact. The recording electrode was connected to an electromyograph (DISA 14 A 30) and the 
stimulation electrode to the output of a stimulator (DISA Ministim, $14 \mathrm{E} \mathrm{10)}$. The stimulus intensity which caused a painful sensation and EMG responses of the least variability in latency and in size was chosen for the final recording.

The flexor reflex responses were averaged by a computer (UNIMAC-4000). For this purpose the output of the EMG amplifier was fed into the computer for summation. The analogue to digital conversion of the computer has a seven bit resolution with a minimum sampling interval of 10 microseconds per sample for the single channel mode. In most of the experiments, the memory of the computer was divided into two or four. Computer analysis time was often 100 to $200 \mathrm{~ms}$. Thirty-two or sometimes 64 and rarely 128 responses were averaged for each stimulation series. The averaged responses were recorded by a Polaroid camera or on a strip chart recorder for measurement.

Three sets of successive BF flexor reflexes were recorded with around 20 to 25 minutes rest intervals, and in the second set, the vibratory stimuli were given simultaneously. The first and third sets were performed without vibration. In 11 subjects, a fourth set of BF reflexes was repeated with vibration.

The vibration apparatus (HEIWA-TVR-HV12-D) used in the study had a cylinder with a long longitudinal axis of $110 \mathrm{~mm}$ and a diameter of $40 \mathrm{~mm}$. The frequency of vibration was $100 \mathrm{~Hz}$. The cylinder was applied to the skin parallel to the longitudinal axis of the foot laterally below the level of lateral malleolus, and fixed manually by one of us. Deviation of the foot from the rest position was avoided by gentle manual fixation during vibratory stimuli. The room temperature was maintained around $29^{\circ} \mathrm{C}$.

\section{Results}

Each electric shock of adequate intensity delivered to the sural nerve at the ankle invariably caused a reflex response in the ipsilateral $\mathrm{BF}$ muscle in all normal subjects. During vibration applied to foot skin innervated by the ipsilateral sural nerve, facilitation of the BF flexor responses was obvious in almost all subjects. Typical examples are illustrated in Figs. 1 and 2. The amplitude of the response was increased and duration was prolonged by simultaneous vibration. In the first set of vibrations, the latency of responses became shorter but this finding was not preserved after the vibration and during the second set of vibratory stimuli. Even the increase of latency occurred progressively. On the other hand, the amplitude and

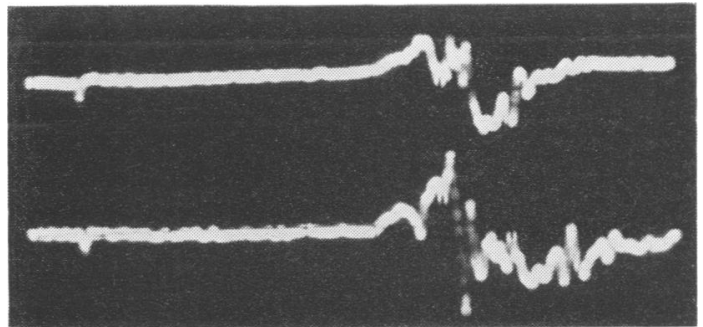

Fig. $1 M O, 22$ year old female. BF nociceptive flexor reflexes before (upper trace) and during vibration (lower trace) applied to the lateral aspect of the skin of the foot ipsilaterally. Each for 32 averaged responses. Calibrations: $20 \mathrm{~ms}$ and $2 \mu \mathrm{V}$.

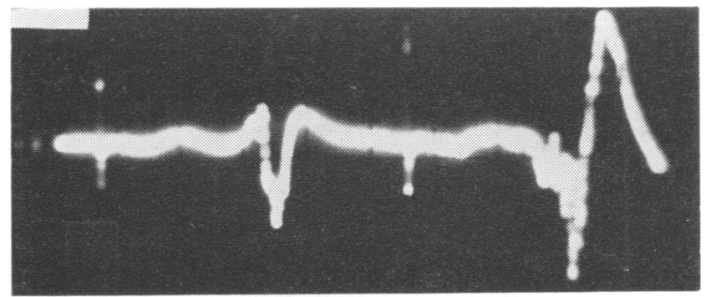

Fig. $2 M Y, 21$ year old female. BF nociceptive flexor reflexes before (left trace) and during (right trace) vibration applied to the lateral aspect of the skin of the foot ipsilaterally. Each for 32 averaged responses. Calibrations: $52 \mathrm{~ms}$ and $10.5 \mu \mathrm{V}$.

duration of the reflex response tended to decrease after the postvibrational period but it was never reduced to the control value of the first set, and the prolonged facilitation remained for as long as 20 to 25 minutes after the vibration.

The statistical results from 25 normal subjects are shown in the Table. Although the mean amplitude and duration of BF reflex was increased during vibration, there was no significant difference between control and vibration values, probably on account of very variable interindividual values in amplitude and duration. The standard deviation and standard error of the mean became large especially for amplitude. Therefore, the results obtained from the four subjects who had amplitudes exceeding $50 \mu \mathrm{V}$ in first control records have been excluded, and a recalculation was made from the remaining 21 subjects. The statistical results are shown in the lower part of the Table. The amplitude $(P<0.01)$ and duration $(P<0.001)$ of the $\mathrm{BF}$ flexor reflex were found to be significantly increased by continuous vibration stimulation in these 21 normal subjects. The mean percentage of size increase obtained from each of 25 subjects is shown in Fig. 3. During vibratory stimulation the amplitude increase averaged $67 \%$ 
Table Mean $\pm S E M$ and standard deviation of vibration effects on nociceptive BF reflexes

\begin{tabular}{|c|c|c|c|c|c|c|}
\hline Subjects & $\begin{array}{l}\text { Latency } \\
(m s)\end{array}$ & & $\begin{array}{l}\text { Amplitude } \\
(\mu V)\end{array}$ & & $\begin{array}{l}\text { Duration } \\
(m s)\end{array}$ & \\
\hline \multicolumn{7}{|l|}{25 normal subjects } \\
\hline Before vibration & $87.5: 2.4$ & 12.0 & $47.5 \div 8.8$ & 44.0 & $55.5: 3.2$ & 16.0 \\
\hline During vibration & $82.5: 2.7$ & 13.5 & $65.4 \div 8.3$ & 41.7 & $72.4 \pm 2.1$ & 10.8 \\
\hline After vibration ( 20 minutes after rest) & $84.9: 3.3$ & 14.7 & $59.4 \pm 11.4$ & 51.3 & $56.2: 4.2$ & 18.9 \\
\hline \multicolumn{7}{|l|}{21 selected normal subjects } \\
\hline Before vibration & $86.8 \cdot 2.7$ & 12.3 & $30.5 \div 3.6$ & 16.4 & $55.6: 3.5$ & 16.0 \\
\hline During vibration & $81.3 \cdot 3.1$ & 14.0 & $49.9 \div 6.4$ & 29.2 & $73.6: 3.8$ & 17.5 \\
\hline
\end{tabular}

Before continuous vibration During continuous vibration After continuous vibration
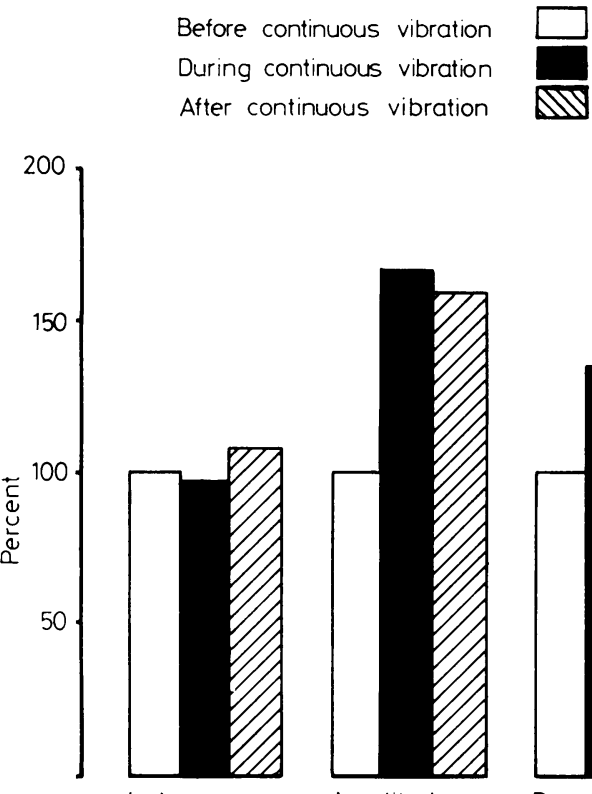

Latency

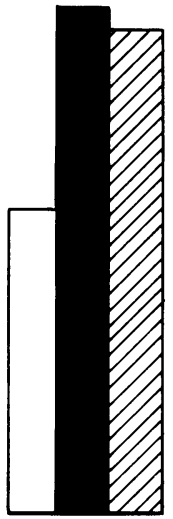

Amplitude

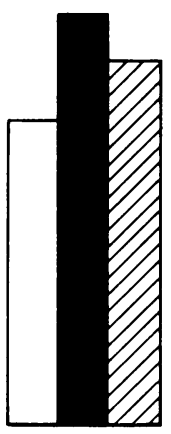

Duration

Fig. 3 Mean percentage of $B F$ nociceptive reflex values during and after vibration in 25 normal subjects. Previbrational values were accepted as 100 and the others were calculated accordingly.

and duration $36 \%$, while the latency was decreased by $7 \%$ during the first vibratory stimulation set. In many cases, the percentage of amplitude and duration of the $\mathrm{BF}$ reflex tended to fall to the previbrational value but never reached it, and remained elevated 20 to 25 minutes after vibration ceased.

In 11 normal subjects, a second set of vibratory stimuli was delivered. Again the size of BF flexor reflex was enhanced above those obtained in the first control and the first postvibratory periods (Fig. 4).

In two subjects, vibration was also applied to the medial aspect of the foot innervated by the posterior tibial nerve. A facilitatory effect was obtained in $\mathrm{BF}$ reflex size almost matching that

when the vibratory stimulus was applied to the lateral aspect of the foot (Fig. 5).

In four subjects, stimulation by vibration was applied to the lateral aspect of the contralateral foot during ipsilateral $\mathrm{BF}$ reflex recording. A similar but lesser degree of facilitation was also found by contralateral vibration (Fig. 6).

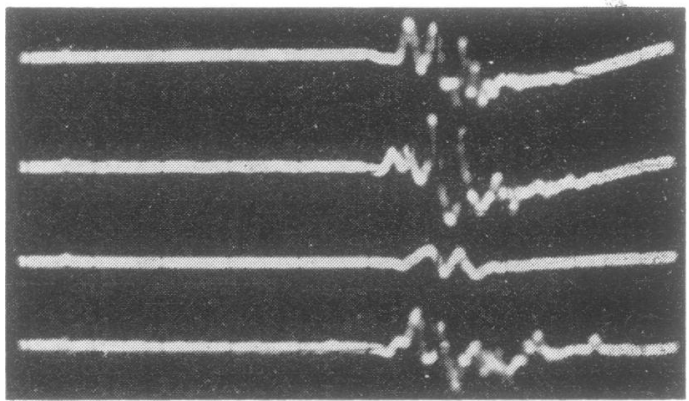

Fig. 4 IE, 23 year old male. BF nociceptive flexor reflexes. From top to bottom: before vibration, during vibration, after vibration, and a second set of averaged responses during vibration. Both the painful and vibratory stimuli were applied at the same site. Each for 32 averaged responses. Calibrations: $20 \mathrm{~ms}$ and $104 \mu \mathrm{V}$.

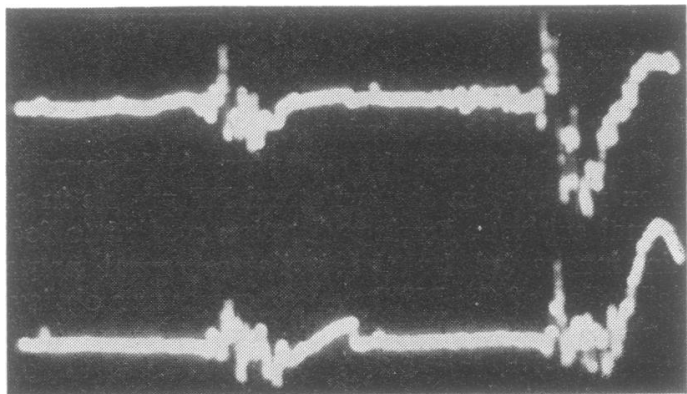

Fig. $5 A K, 23$ year old male. $B F$ nociceptive flexor reflexes. Upper traces are the responses obtained before (left) and during (right) vibration applied to the lateral aspect of the foot. Lower traces are the responses before (left) and during (right) vibration applied to the medial aspect of the foot. Each for 32 averaged responses. Calibrations: $50 \mathrm{~ms}$ and $40 \mu \mathrm{V}$. 


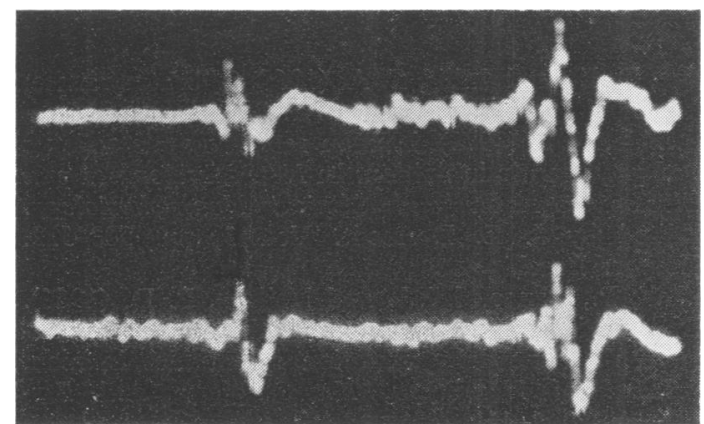

Fig. $6 A H, 25$ year old male. $B F$ nociceptive flexor reflexes. Upper traces are the responses obtained before (left) and during (right) vibration applied to the lateral aspect of the foot ipsilaterally. Lower traces are the responses obtained before (left) and during (right) vibration applied to the skin of the contralateral foot (lateral side). Each for 32 averaged responses. Calibrations: $50 \mathrm{~ms}$ and $41.5 \mu \mathrm{V}$.

Ipsilateral vibration was applied to the Achilles tendon and no BF reflex facilitation was observed in one subject. In another subject, vibratory stimuli were delivered to the palmar surface of the hand; again no significant change was seen.

The subjects often described the painful electrical shocks at the ankle as brisk, pulsatile, and pricking pain located maximally at the stimulation site-that is, behind the lateral malleolus. The pain was reported to radiate above and below the stimulation site, and it was difficult to delineate precisely the area of pain which was often less than that of the site stimulated locally. During ipsilateral vibration, the pain was more precisely localised at the lateral malleolus and even became more intense locally, but the radiation of pain was either reduced or abolished in 14 subjects, including one of us (DA). In the remaining 11 subjects the effect of vibration on pain sensation differed in other ways. There were no differences in pain sensation and its radiation before and during vibration in seven, while four subjects reported that the pain felt previously was just increased in degree during vibration. Contralateral foot vibration did not alter the electrically induced pain sensation. No significant relation was found between changes of the BF reflex and the perception of pain sensation described during vibration.

\section{Discussion}

In previous studies on vibration-induced reflexes there were few reports of withdrawal reflexes produced during vibration applied to the muscle or tendon surface (Hagbarth and Eklund, 1968; Hag- barth, 1973; Lance et al., 1973). Delwaide (1973) reported that a polysynaptic reflex response evoked from the soleus muscle was increased in size during vibration applied to the Achilles tendon. In the present study it was demonstrated that BF nociceptive flexor reflexes elicited by painful stimulation of the sural nerve at the ankle are in fact facilitated by continuous segmental vibration at $100 \mathrm{~Hz}$ frequency.

The facilitation of nociceptive BF reflexes, shown by an increase in amplitude and duration of the response under vibration, is reproducible in the individual, and has cumulative effects demonstrable up to 20 minutes after cessation of vibratory stimuli. These features bear some similarities to other reflex phenomena of sensitisation, habituation, and dishabituation. There is a reflex sensitisation phenomenon in human flexor reflexes when successive electrical pulses are delivered at one per second or less frequently within one set of stimuli (Wirski and Hugon, 1972), whereas some kind of habituation of the flexor reflexes is recognised during longlasting regular stimuli after transient facilitation (Dimitrijevic̀ and Nathan, 1970). The habituated response in spinal man can easily be dishabituated by introducing an extra stimulus close to or far away from the site of original stimulation (Dimitrijevic and Nathan, 1971). Since the reiteration facilitation of $B F$ reflexes remains only ipsilateral in normal subjects (Wirski and Hugon, 1972) and in combined stimulus series, dishabituation of the flexor responses quickly disappears after approximately 25 combined stimuli (Dimitrijević, 1973); the bilateral facilitatory effects of vibration applied separately to the skin of both feet in our normal subjects could not easily be explained by reflex sensitisation. Dishabituation cannot be the main cause of vibratory facilitation because stable and continuous augmenting oscilloscopic EMG responses have been observed throughout in the vibratory stimulation period. The cumulative longlasting facilitatory effect in the postvibratory period is less dense than the facilitation obtained during vibration and is also difficult to explain in terms of sensitisation and dishabituation. Furthermore, the application of the vibration to the palmar surface of the hand in one subject and to the Achilles tendon in another did not produce facilitation of the BF reflexes. These observations may indicate that the attention must also play a minor role in vibratory segmental facilitation.

Since the vibratory stimuli predominantly activate the large diameter muscle nerve afferent nerve fibres (Hagbarth and Vållbo, 1968), it is reasonable to propose that continuous vibration 
applied to the lateral aspect of the skin could also activate the large myelinated skin and, especially, subcutaneous receptors in man (Calne and Pallis, 1966). Therefore, the facilitatory effects are produced mainly by afferent inputs carried by large skin and subcutaneous afferent fibres, but the role of articular and muscle afferent fibres still remains to be clarified with regard to possible spreading of the vibration.

The site(s) and operational level(s) of the facilitation of the BF nociceptive reflexes remain speculative. Postsynaptic facilitatory effects may be evoked during continuous vibration. It might be suggested that the prolongation of the facilitation 20 minutes after vibration is compatible with the repetitive longlasting after-discharges of the flexor interneurones (Lundberg, 1966), and the motoneurone pool of the BF muscle does not seem to be involved directly. During vibration many afferent nerve terminals and interneurones are occupied by very dense successive and continuous segmental inputs. Tremendous transmitter depletion may result, probably in inhibitory spinal synapses and inhibitory spinal and supraspinal descending synaptic mechanisms linked with flexor reflexes (Lundberg, 1966).

After stimulation of the sural nerve trunk by painful electric shocks, two kinds of afferent inputs to the spinal cord (tactile and nociceptive) are activated. In terms of the gate control theory of Melzack and Wall (1965), it is suggested that the dense activation of A-delta fibres and probably of $\mathrm{C}$ fibres dominate the total input so that the "gate" is opened for pain and for nociceptive reflexes. In order to balance between two kinds of inputs, cutaneous vibration has been applied segmentally, and the dominance of afferent input was deviated in favour of the larger myelinated afferent fibres from the skin. From this theory it would be predicted that the pain would be alleviated and the nociceptive flexor reflex reduced at least in some degree. But, on the contrary, nociceptive reflexes were facilitated even with contralateral vibratory stimuli and longlasting cumulative effects were observed. Pain sensation did not change significantly. Although 14 subjects described that the radiation of the pain was abolished or diminished, the pain under the stimulation site became even more intense, and the remaining experimental subjects responded irregularly. These clinical and electrophysiological findings obtained from normal subjects do not seem to be easily explained by the gate control mechanism, and serious objections to the theory have been presented recently (see Nathan, 1976).

\section{References}

Calne, D. B., and Pallis, C. A. (1966). Vibratory sense: a critical review. Brain, 89, 723-729.

Delwaide, P. J. (1973). Human monosynaptic reflexes and presynaptic inhibition. In New Developments in Electromyography and Clinical Neurophysiology. Edited by J. E. Desmedt. Vol. 3, pp. 508-522. Karger: Basel.

DeGail, P., Lance, J. W., and Neilson, P. D. (1966). Differential effects on tonic and phasic reflex mechanisms produced by vibration of muscles in man. Journal of Neurology, Neurosurgery, and Psychiatry, 29, 1-11.

Dimitrijevic, M. R. (1973). Withdrawal reflexes. In New Developments in Electromyography and Clinical Neurophysiology. Edited by J. E. Desmedt. Vol. 3, pp. 744-750. Karger: Basel.

Dimitrijevič, M. R., and Nathan, P. W. (1970). Studies of spasticity in man. IV Changes in flexion reflex with repetitive cutaneous stimulation in spinal man. Brain, 93, 743-769.

Dimitrijevič, M. R., and Nathan, P. W. (1971). Studies of spasticity in man. V Dishabituation of the flexion reflex in spinal man. Brain, 94, 77-90.

Eklund, G., and Hagbarth, K. E. (1965). Motor effects of vibratory muscle stimuli in man. Electroencephalography and Clinical Neurophysiology, 19, 619.

Ertekin, C., Ertekin, N., and Karcioglu, M. (1975). Conduction velocity along human nociceptive reflex afferent nerve fibres. Journal of Neurology, Neurosurgery, and Psychiatry, 38, 959-965.

Hagbarth, K. E. (1973). The effect of muscle vibration in normal man and in patients with motor disorders. In New Developments in Electromyography and Clinical Neurophysiology. Edited by J. E. Desmedt. Vol. 3, pp. 428-443. Karger: Basel.

Hagbarth, K. E., and Eklund, G. (1968). The effects of muscle vibration in spasticity, rigidity and cerebellar disorders. Journal of Neurology, Neurosurgery, and Psychiatry, 31, 207-213.

Hagbarth, K. E., and Vållbo, A. B. (1968). Discharge characteristics of human muscle afferents during muscle stretch and contractions. Experimental Neurology, 22, 674-694.

Hugon, M. (1967). Reflexes polysynaptiques cutanés et commande volontaire. Thesis, Paris.

Hugon, M. (1973). Exteroceptive reflexes to stimulation of the sural nerve in normal man. In New Developments in Electromyography and Clinical Neurophysiology. Edited by J. E. Desmedt. Vol 3, pp. 713-729. Karger: Basel.

Lance, J. W., Burke, D., and Andrews, C. J. (1973). The reflex effects of muscle vibration. In New Developments in Electromyography and Clinical Neurophysiology. Edited by J. E. Desmedt. Vol. 3, pp. 444-462. Karger: Basel.

Lundberg, A. (1966). Integration in the reflex pathway. In Nobel Symposium I, Muscular Afferents and Motor Control. Edited by R. Granit. pp. 275305. Almquist and Wiksell: Stockholm. 
Melzack, R., and Wall, P. D. (1965). Pain mechanisms, a new theory. Science, 150, 971-979.

Nathan, P. W. (1976). The gate-control theory of pain: a critical review. Brain, 99, 123-158.

Rushworth, G., and Young, R. R. (1966). The effect of vibration on tonic and phasic reflexes in man.
Journal of Physiology, 185, 63-64.

Wirski, J., and Hugon, M. (1972). Facilitation of cutaneous muscular reflex in man obtained by reiteration of painful stimulus. In Neurophysiology Studied in Man. Edited by G. G. Somjen. pp. 350365. Excerpta Medica: Amsterdam. 